Running head: Situating Graphs as Workplace Knowledge

\title{
Title: Situating Graphs as Workplace Knowledge
}

Authors: Richard Noss, Arthur Bakker, Celia Hoyles and Phillip Kent

Affiliation: London Knowledge Lab, Institute of Education, University of London Address: 23 - 29 Emerald Street

London WC1N 3QS

United Kingdom

Tel: +442077632150 (2154)

Fax: +44 2077632138

Email: r.noss@ioe.ac.uk 


\section{SITUATING GRAPHS AS WORKPLACE KNOWLEDGE}

ABSTRACT. We investigate the use and knowledge of graphs in the context of a large industrial factory. We are particularly interested in the question of "transparency", a question that has been extensively considered in the general literature on tool use, and more recently, by Michael Roth and his colleagues in the context of scientific work. Roth uses the notion of transparency to characterise instances of graph use by highly educated scientists in cases where the context was familiar: the scientists were able to read the situation "through" the graph. This paper explores the limits of the validity of the transparency metaphor. We present two vignettes of actual graph use by a factory worker, and contrast his actions and knowledge with that of a highly-qualified process engineer working on the same production line. We note that in neither case were the graphs transparent. We argue that a fuller account that describes a spectrum of transparency is needed, and we seek to achieve this by adopting some elements of a semiotic approach that enhance a strictly activity-theoretical view.

KEY WORDS: graphs; situated abstraction; technology; transparency; workplace mathematical knowledge 


\section{INTRODUCTION}

Tools and technologies, conceived in the widest sense, shape the ways in which people make sense of the world, talk about it, think about it and act upon it. Starting from the ways in which the mathematical knowledge of learners is transformed by the computer's presence, we have increasingly come to focus more generally on the transformations of knowledge in interactions with computers in mathematics classrooms (see Noss and Hoyles, 1996b) and in workplaces - the focus of this paper (see, for example, Noss, Pozzi and Hoyles, 1999). These transformations of mathematical meanings generated in activity, necessitate a conception of mathematical epistemology, which properly accounts for the specificity of situations and the contingencies of mathematical expression on tools and technologies as well as the discourses of the communities in which they are used. Put another way, while our focus on workplaces will encourage us to conceive of mathematical discourse in a broad sense that transcends that of conventional, "school" mathematics, we will also need to develop a language that allows us to describe what individuals are doing and, at least by implication, thinking at a mathematical level.

Digital technologies can "informate" (in the sense of Zuboff, 1988) cultures and communities and - the specific interest of the current paper - production systems, by making accessible hitherto invisible facets of process. As Zuboff points out, information technology not only produces action but also produces a voice that renders events, objects and processes so that they "become visible, knowable, and shareable in a new way" (p. 9), and a way that is symbolic and - as we will argue mathematical. Our concern is better to understand this new way, and how the process of becoming visible is shaped by the activity system of the workplace, by tool 
mediation, the work communities, and the rules and division of labour (Engeström, 2001). It is evident that this informating of the workplace does not take place of itself, and the degree to which such transformations occur is the degree to which informating has been integrated into the activity system; it is perfectly possible to ignore or circumvent accessible information. As Nathan et al (2003) have argued in the context of analysing effective use of technology at work; "what organisations do or fail to do - with technology is a more important predictor of success than any technical specification" (p.3).

Knowledge is shaped by pre-technological as much as technological representational systems. Yet technological tools possess the added dimension of producing signs that mediate what is perceived and what is expressed; for sign users it is as if the signs themselves take on a life of their own, and indicate what does and does not matter in external reality. To the knowledgeable user, graphs generated by a computer system for example, do not simply describe, they can indicate what the salient variables are in a system, and point to what is significant in relations between them. Such graphs can also afford the potential for persons to change what they see, while at the same time rendering some aspects of the graph invisible.

In a number of our own studies we have discovered repeatedly how workers as diverse as bank employees and nurses, tend to populate abstract representations with meanings derived from everyday experience, thus situating abstractions in familiar contexts. For example, in our interviews with nurses around the blood pressure charts of babies, we noted how the nurses superimposed on the chart a personal narrative of what the baby might have been doing and his possible state at the time of the readings (see Noss et al, 1999). Thus the nurses situated the graphs as representations of relations between quantities so that the abstract relationships between graphical 
elements would refer to plausible (but hypothetical) actual events that could have generated these relationships. In our work with investment bank employees, we similarly saw bankers read graphs by reference to the behaviour of particular financial instruments rather than representing general functional relationships (Noss and Hoyles, 1996a).

Our conviction that the "meaning" of graphs exists in their close integration with the work context raises the issue of the transparency of signs. Transparency is discussed in school-based research (see, for example, Meira, 1998), but here we focus on the work of Roth and his colleagues because of their extensive investigatations of graph use in the workplace. Roth and Bowen (2003) showed that expert scientists had difficulty interpreting graphs when they were unfamiliar with the entities represented and with the procedures that translated the entities into graphs. However by contrast, Roth $(2003 \mathrm{a}, \mathrm{b})$ claims that in competent use in familiar situations, scientists' use of graphs becomes transparent, in the sense that they seem to deal directly with a phenomenon without apparent mediation:

When the scientists and technicians are very familiar with certain graphs and the phenomena these stand for, the relation is no longer that of sign and referent. They seemingly access the phenomenon directly, as if the graphs had become transparent in use. (2003a, p. 161-162)

He compares the idea of transparency with wearing spectacles - only when they are new do they impinge on awareness.

One of the questions we pose in the current paper is whether this transparency is typical of all graph users who are familiar with the situation modelled by the graph, or whether there is something specific to a scientist's knowledge that produces this transparency: after all, scientists are trained in the discourse of symbolic graphical 
relationships, so this mathematical discourse is for them a "situation" as richly endowed with meanings as any "concrete" context.

There are two possibilities. The first is that transparent use of graphs is a characteristic of familiarity in general, so we would expect for example to see factory operators, as much as scientists, involved in the same kinds of interactions (possibly on different time scales) and developing the same kinds of interpretations of the graphs. The other possibility is that there are particularities involved in different activity systems, which means that transparency takes on a different character, or does not occur in the form described by Roth. In this latter case, we would want to explore the limits of validity of the transparency metaphor, and in particular, its relationship to familiarity with context on the one hand and symbolic discourse on the other.

In this paper, we explore these questions through an analysis of two vignettes derived from actual use and interpretation of computationally-generated graphs by different participants in the workplace, with contrasting expertise and experience.

\section{SETTING AND METHOD}

The research forms part of the Techno-mathematical Literacies in the Workplace project $^{\mathrm{i}}$, a 3.5-year study which has sought to investigate how techno-mathematical knowledge is negotiated and transformed across boundaries within workplaces. The project is investigating Techno-mathematical Literacies (TmL) in three different industrial and commercial sectors (packaging, pharmaceuticals manufacturing and financial services), where we characterise $\mathrm{TmL}$ to be the mathematical knowledge mediated by tools that is functional and grounded in the context of a specific work situation. For each sector, a sample of between two and four companies was 
established, to work with us over the period of the research, initially as sites for ethnographic observation and description of TmL, and later as co-designers of workbased TmL training using as a basis, situations derived from the ethnography and mathematical artefacts (such as graphs) found within the workplace.

This paper focuses on analyses from the first phase of the research. The two vignettes were selected after collecting data over a period of 12 months in one packaging factory during which time we made multiple visits to the factory, undertook observations of and interviews with the workers and conducted email exchanges and telephone conversations to clarify and discuss issues of relevance. The data-collection became progressively focused over the year, beginning with our first encounter with an incident, a recognition on our part that this was "interesting" from the perspective of TmL, and gradual elaboration of the whole picture (or as much of it as was possible for us to gain) through multiple methods. Our general method (followed in this case) is to organise feedback and validation meetings for the purposes of triangulation. In feedback meetings, which are company specific, we present our findings to a group of managers in the company and discuss how far they resonate with their own experience. In broader validation meetings, we present our conclusions to managers from different companies within the sector in order to draw out similarities and differences.

Both of the vignettes took place in a company that manufactures thin transparent packaging film (e.g. for wrapping food). Our observations covered all four manufacturing areas on the site: film extrusion, the conversion of raw plastic "granules" into thin film by melting and stretching; barrier extrusion, the production of a sophisticated multi-layer film which are separately converted into food bags; 
bag-making, the conversion of film into bags by cutting and sealing, and printing of customer-specified logos or information on bags.

The vignettes concern the struggle for shared meaning around graphs that are automatically produced from data collected at different points in the production process. The central figures in both vignettes are Carol, a process engineer, and Jim, a shift leader. Carol has a degree in chemical engineering and had worked in the plant for 2 years. She was our major source of information about the production process: she showed us around all four areas of the factory, as well as giving us a detailed description and two additional tours of the film extrusion area, which had become the focus of our research. She answered all our questions (face to face or on email) and was able to help us understand the complexities of the manufacturing process as well as the graphs of historical data that were generated in the factory. Carol inspected the graphs over a five-hour time span as part of her routine work: "It would be an unusual day when I didn't look at a graph". This allowed her to become aware of the "shapes" of the graphs in normal conditions so she could detect abnormalities.

Jim has no post-16 education, but had 31 years' experience of working in the factory. He tried to ensure that his shift achieved its targets and was proud of his ability to solve problems. He described himself as "a trouble-shooter" asserting: "I like the challenge. If there is a problem I give my best shot to do whatever I have to do to make it right. I like to be a winner, if you like." His approach to trouble-shooting was as soon as a problem was reported to him, he would look at the graphs of historical data. The challenge we set ourselves was to try to understand the TmL that Jim used when he looked at these graphs: on what it was based, how it had been developed and how it could be better described and communicated. 
We visited the factory on nine occasions, during which time we observed the incidents at the core of the two vignettes. We then dedicated five visits (of between 1.5 and 3 hours each, with two or three researchers per visit) to investigate Jim's and Carol's perspectives on the incidents and the role the graphs played, as well as to gain a broader picture of how the incidents fitted into the broader set of activity systems of the factory. Our vignettes concern film extrusion, and given that the reader is unlikely to be familiar with this process, we begin our story with a closer description of its essential features.

\section{THE EXTRUSION PROCESS IN THE PRODUCTION OF PLASTIC FILM}

In a factory producing transparent packaging film, the thickness or "gauge" of the film is critical. The production operators, shift leaders and process engineers are all concerned with variations of tenths of a micron in film thicknesses of 15 to 20 microns (a micron is $1 / 1000^{\text {th }}$ of a millimetre). Thus a crucial aspect of the object of activity for the workers in the factory is actually invisible. It is only perceivable through the mediation of measuring instruments, electronic process control systems and mathematical (graphical and numerical) representations of information ${ }^{\mathrm{ii}}$. Added to this invisibility is the overall complexity of the extrusion process, which involves about twenty steps: the plastic starts from raw granules, is melted to form a thick tube, which travels through several stages as a flat "tape" and is then extruded (stretched) at different temperatures and tensions (that need to be very precisely controlled), becoming thinner at each stage until the desired thickness is reached.

The most sensitive stage of the extrusion process is at what is known as "the bubble" - where the tape is inflated with compressed air so that it expands by a factor of about 
25. (The bubble can be up to $1.5 \mathrm{~m}$ wide and about $6 \mathrm{~m}$ high; think of blowing air into a deflated balloon). After inflation the tape is called "film" and at the top of the bubble the film is slit and rolled onto rollers, yielding the end product of this process.

A team in the extrusion area consists of six people: a supervisor in charge for the purposes of team management, three shift leaders, who are all experienced operators (in some cases more than 20 years) and two operators. Technical process problems are shared across the team. Each extrusion line is controlled by a computer system that monitors and records numerous process parameters - typical display screens (see Figure 1) present "flow diagrams" representing actual quantities and flows such as the temperatures and pressures at different points in the line, or the amounts of raw materials in input hoppers. The computer system records all these process data and keeps them as historical data for several months. These historical records are accessible to all, although our ethnography indicated that shift leaders and operators rarely if ever engaged with them or even looked at them. Jim was an exception.

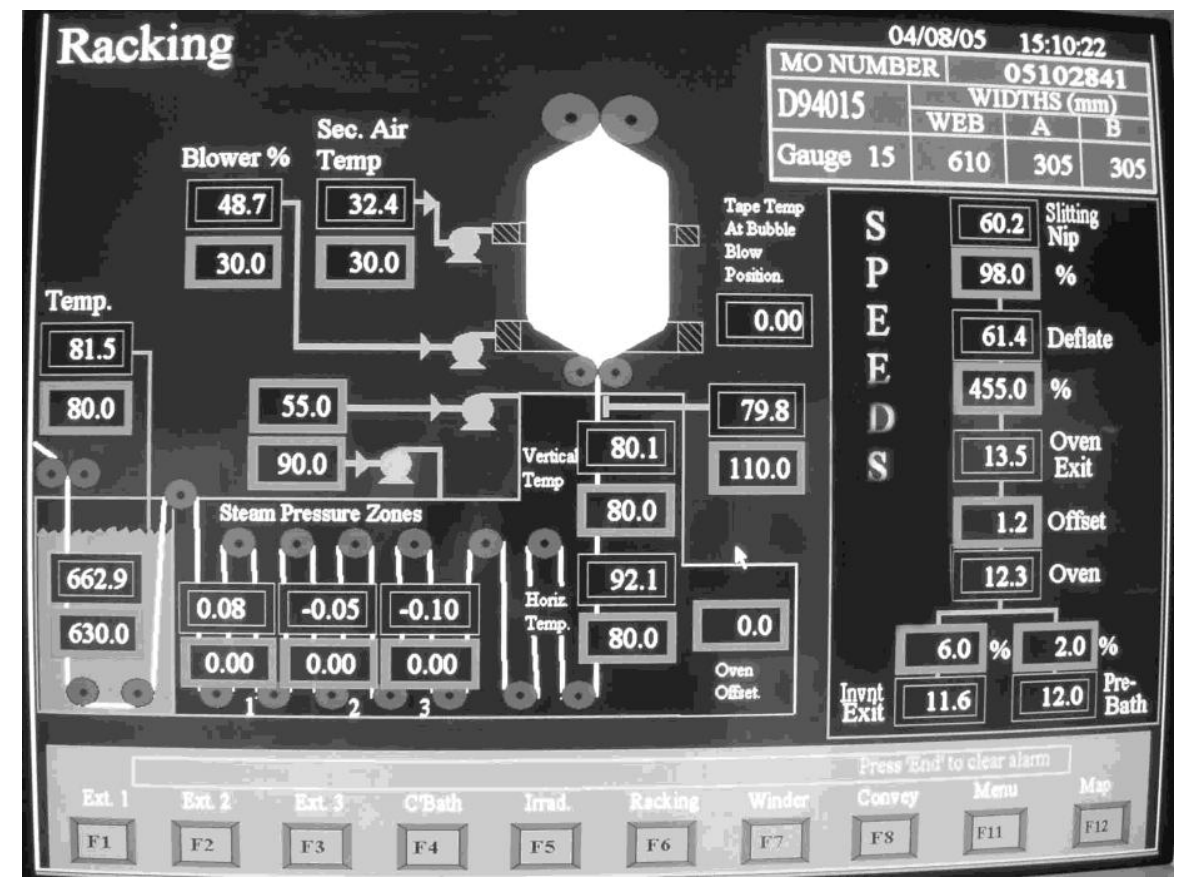

Figure 1. Screen shot of a part of the extrusion computer control system. White "thread" shows the 
flow of the film through various production stages, with temperatures, pressures, etc. displayed. The bubble is represented as a hexagonal white area.

We investigated the historical data ourselves and found it was possible to view graphs of the variation over time of quantities, such as amount of raw material consumed, temperatures at various points in the process, pressures of heating steam in various "baths", speed of the tape flow at various points, and tensions of the film at various points. We also discovered that to interpret the graphs, the reader needs to have considerable knowledge of the production process as well as of reading graphs: essentially, this is the techno-mathematical literacy under investigation in the following analysis.

\section{FIRST VIGNETTE: DIPS IN A GRAPH}

The production area of particular interest for the first vignette is at the two inventories in the production line. These inventories provide spare capacity in case something goes wrong in the process. For instance, if the end of the process has to be stopped (because, say, the bubble bursts), the beginning part of the process can continue to run for about ten minutes by storing the output of tape up to that point on an inventory. Each inventory consists of two sets of rollers, one fixed and one movable, which are kept apart at a distance between about 2 to 10 feet (Figure 2 shows one inventory). A pressure machine is set to a constant value, a "set point", which then gives a (slightly variable) tension to the wire that is tied to the movable set of rollers. For the smooth running of the production line, it is important that there is little variability in this wire tension so as to avoid uneven stress on the tape that is rolling through the inventory. Figure 3 shows an example of the graphs produced using the historical data at this 
point in the process. It shows the set points at the two inventories, the two straight horizontal lines at 21 and 23 bar, and the resulting tensions on the tape, which were in kilograms (the scale shown on the display depends on the variable selected). Notice that the display shows four graphs simultaneously with some units of measurement invisible while some units (such as position of the movable inventory rack) are converted into percentages.

We have spent much time trying to make sense of graphs in the absence of either scales, units to distinguish the quantities and any intimate knowledge of process. Some variation would be expected at all times for most of the quantities, since conditions vary slightly depending, for example, on the atmospheric temperature, pressure and humidity, or small variations in the physical properties of the raw materials. But it struck us that in order to make any meaningful interpretation of the graphs and to exploit the historical data function, the graph reader needed to know what to look for: what were the significant quantities in the process, what might be significant in the variations in these quantities and how to recognise changes in the relationships between the quantities.

The graphs shown in Figure 3 were derived, we were informed, at that particular time when the process was stable, with rather less variation in the tension graphs than normal. The scale on the horizontal axis is about 75 minutes between the (vertical) scale lines and the vertical scale in bar. Given the complexities in reading the graphs, not least because of the many extraneous lines in evidence, we have reconstructed the originally coloured graph in Figure 4, to clarify the relationship between set point and tension, to suppress irrelevant information and to clarify the scales on the axes. 


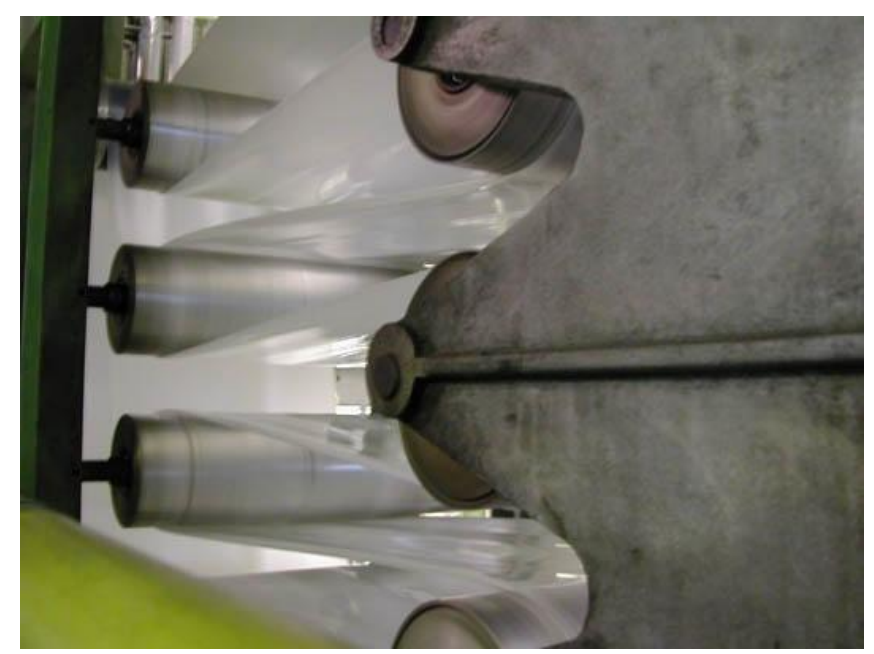

Figure 2. Picture of an inventory - here rollers are about 2 feet apart

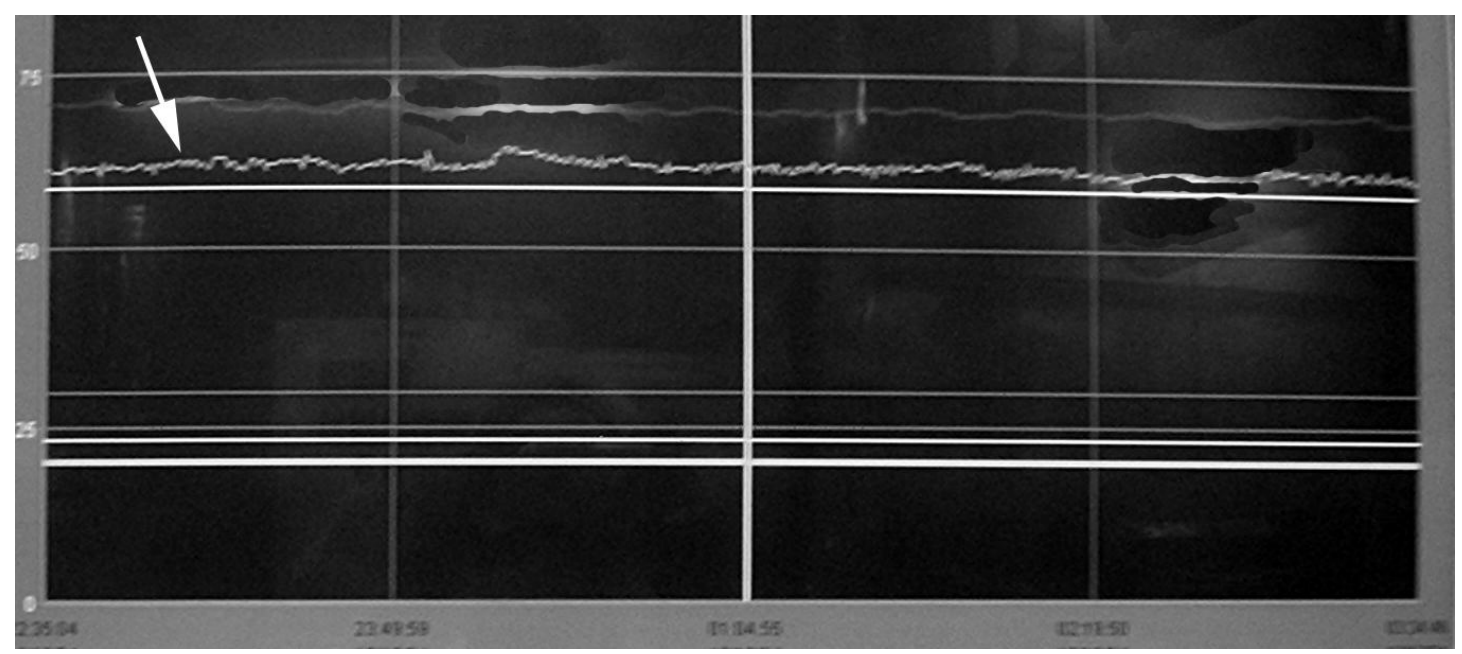

Figure 3. An example of a screen derived from the historical data at the inventory points (here of a period when the tensions on the tape were stable) 


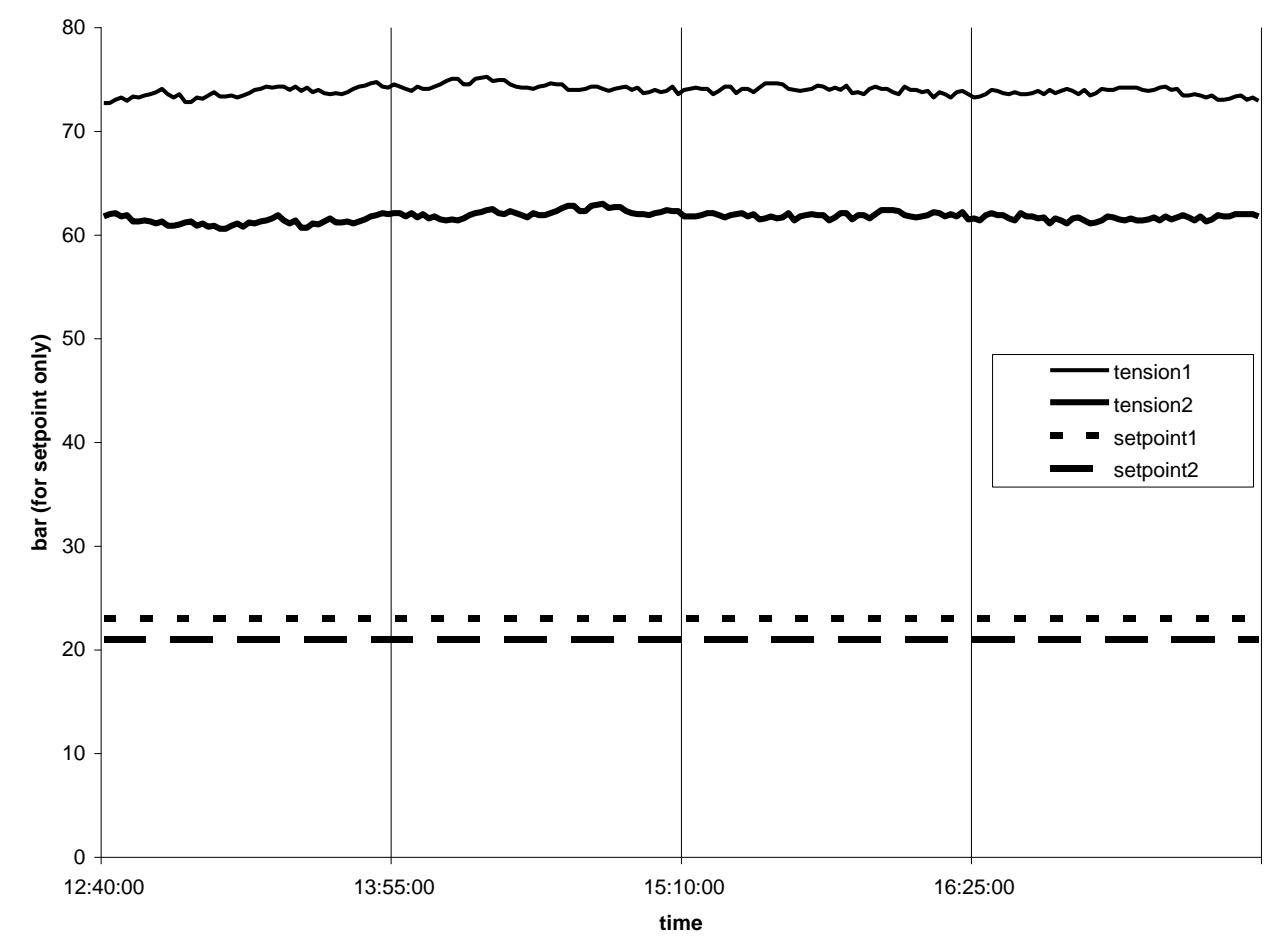

Figure 4. Our reconstruction of Figure 2 without "extraneous" lines and information and with clearer information of axes and scales. The vertical scale in bar only applies to the set points. If a tension graph is selected, a different scale appears (between 10 and $20 \mathrm{~kg}$ ).

The display of the historical data is designed for use by professional engineers, not with the interests of production staff in mind. Despite the complexities of how historical data are represented in the computer system, a few members of the production staff, including Jim, did look at these data and had learned to "read" the graphs. What they read and how they read them is an issue we investigated further.

In normal production, the extrusion bubble is stable. However, in the first vignette the bubble was observed on the shop floor to be unstable. In Carol's words, there were "periods where it would wallow in and out; it would become big and small and very unstable; it would burst and we couldn't find any obvious causes for that". This instability had been an intermittent problem for several months and its cause had not 
been identified. When Jim encountered the problem, he looked at the historical data in the computer system, as we have noted browsing the "historics" had become his habit over quite a number of years. Carol told us:

There are four older guys who use the historical data significantly, and they all have $15+$ years' experience. Perhaps out of pride, they prefer not to ask me about problems and will look at the historical data first. I think only 4 people use that data [out of about 30 people], the rest don't use it at all - some of the supervisors don't know how to access it.

Thus to investigate the intermittent stability problem, Jim scrolled through the many pages of historical graphs trying to find anything unusual that had occurred at the times bubble instability had occurred. He then noticed by reference to the inventory graphs that when the bubble was unstable the tension in the tape at one of the inventories became quite changeable. Carol described what he did:

Jim went through all the graphs and tried to find anything that he thought looked "odd" that was his expression. Because he looks at graphs often, he has learned what looks normal, what's a normal fluctuation and in his opinion when he looked at the graph of the tension in the inventory it seemed that there was an abnormal pattern of fluctuation that corresponded to the moment when we'd had the instability in the extrusion bubble.

Instead of the flat wiggly lines as in Figure 3, Jim noticed what he called a "dip". When we asked him to sketch what the dip looked like, he first said he found it hard to remember, but then was willing to simulate it (with a pen) on a print-out of another day (see Figure 5). As we were surprised about the smoothness of his sketch, we asked him if the line really looked so smooth. It turned out that for his sketch, he ignored small, "wiggly" variation and referred to the line as "smooth". 


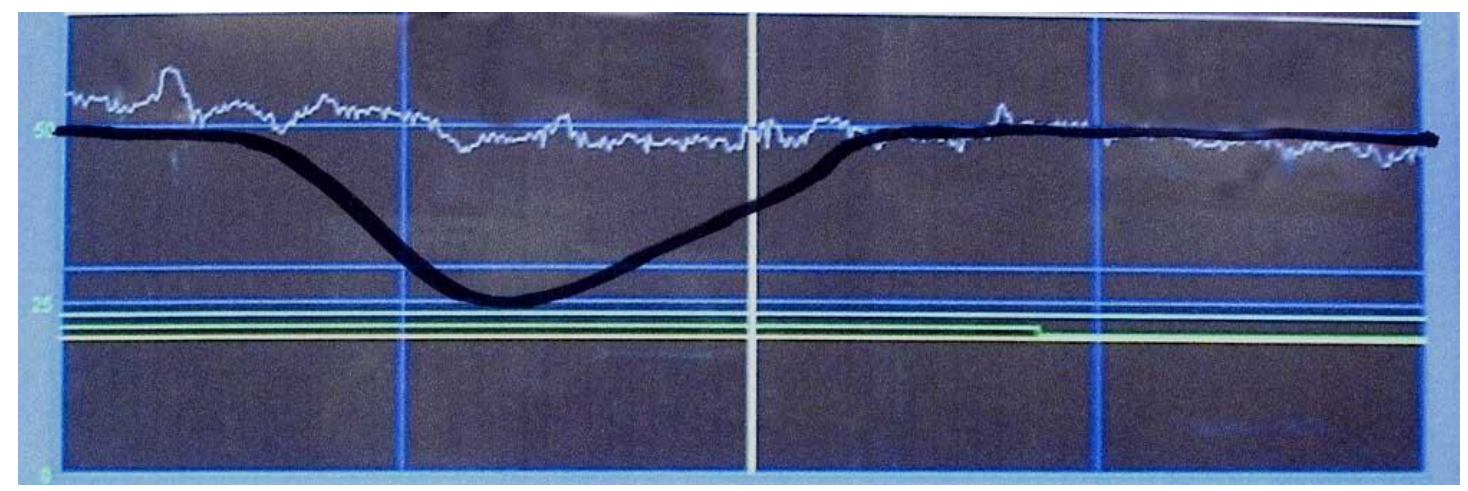

Figure 5. The thick black line shows Jim's own sketch of the "odd" looking "dip" he had noticed in the tension graph.

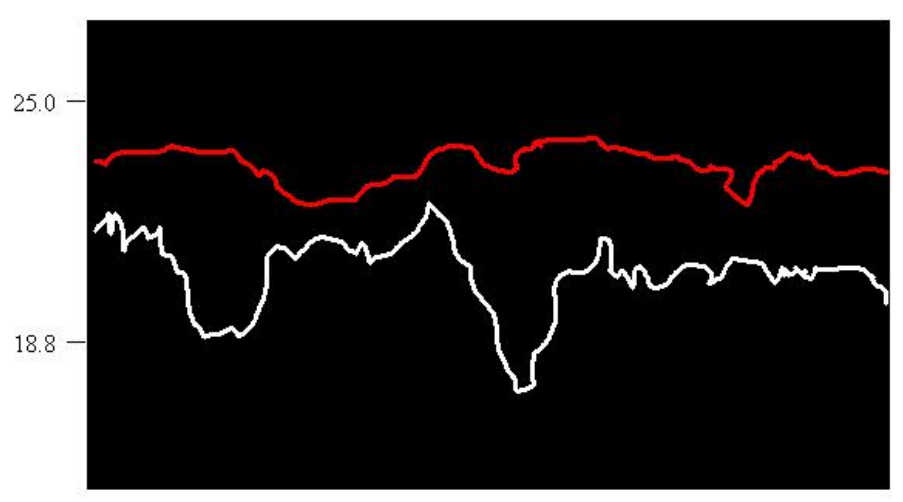

5 hours

Figure 6. Screenshot of actual historical data- the lower line showing two dips that Jim judged as "odd"

After the interview with Jim, Carol sent us a screenshot of the actual historical data at the two inventories at the time of the instability (Figure 6). Again, in order to highlight the relevant features and to assist readability, we reconstruct the graph in Figure 7. Notice that there was much more variation in the tension of one of the tapes than in stable periods (compare with Figure 4). Also note that the tension lines now appear at a different location on the scale than in Figure 4, but this does not imply anything about its absolute value. In fact, the lower line might start at a higher absolute value than the upper line. 


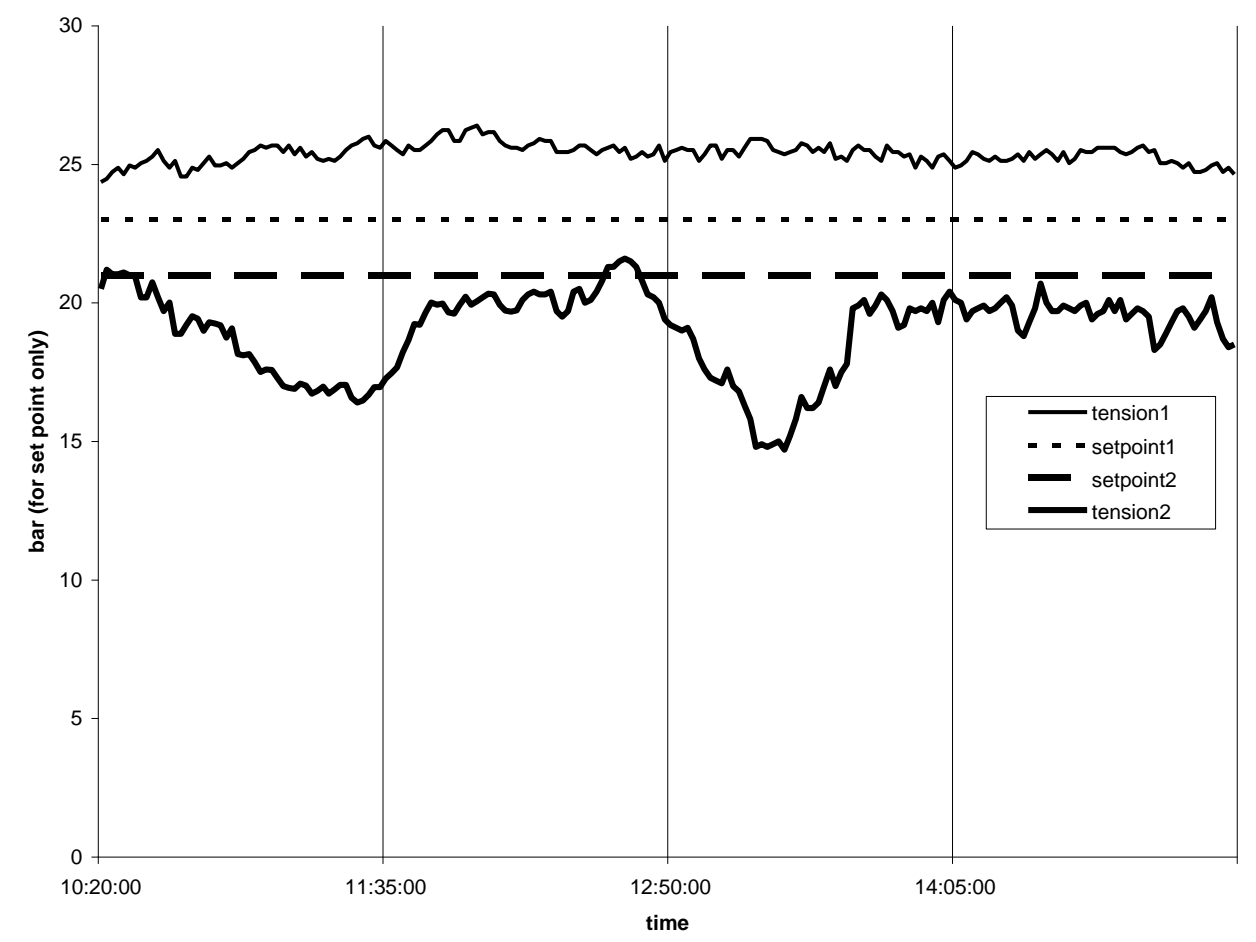

Figure 7. A reconstruction of the screenshot of the historical data at the inventories showing the two set points and corresponding tension graphs at the time of instability. Again, the scale only applies to the set points.

Once Jim had identified that one inventory might be the site of the problem, he informed Carol, who asked the maintenance engineers what might be causing such behaviour. They did not know of a cause but decided to open up the rollers of the pressure system (which had not been inspected for some 15 years) and found that the bearings inside the rollers were seized up. The resulting variable tension on the movable set of rollers caused the tape to be stretched unevenly, and it was this that ultimately led to the bubble's instability later in the process.

Jim's involvement in solving the problem was crucial. His breakthrough was to pinpoint where in the process (out of potentially dozens of possible locations) the problem might be and he did this by reading the graphs. Is this interpretation of the 
graphs obvious? After all, when comparing the variation in the two reconstructed graphs (Figures 4 and 7) it seems clear that the second tension line was very variable. But there are several issues. First the graphs are not generally regarded as useful. As Carol, explained:

No [it is not obvious], you have to specifically go and look for it, it is not normally displayed. That's why none of the other shift leaders noticed. The inventories normally sit there and work - nobody looks at the graphs for them, apart from Jim, who looks at the graphs for everything.

So the graphs first have to be recognised as worthy of attention. Second, as mentioned earlier, the graphs are hard to read given the type and complexity of the displays: this is the reason why we have offered our reconstructions. Further, a variable tension such as shown in Figures 6 and 7 does not necessarily indicate a problem. To our surprise, Jim told us during the interview that such wild variation in the tension could happen even if there was no serious problem. When we asked him, "When you see a graph like that (Figure 6), what goes through your mind?" he answered, "Well, if I've got quality rolls, I wouldn't make an alteration." In other words, the "meaning” of the graphs depended first on detecting a production problem that required some action to be taken. Thus the graph was neither simply a representation of a problematic tension caused by an unstable pressure system, nor was it transparent to Jim or Carol. Rather it indicated a possible location of a problem already reported.

\section{SECOND VIGNETTE: STRAIGHT LINES IN GRAPHS}

A few days after we spoke to Carol about the first vignette, Jim again used historical data to identify the source of a problem. This time it was a problem with one of the 
feeders of the plastic into the extruders before the granules are made into the tape. Carol told us what Jim had done:

By examining the "revs [revolutions] per minute" historical data and seeing that it wasn't fluctuating as Jim expected but was a constant value, he determined something was wrong with it. He alerted the maintenance engineers who found the motor on the controller had been fitted to run backwards after some work done on it the previous day and so the signal it was sending for revs per minute was false. Jim doesn't know anything about motor control - he just knew that the historical data looked "wrong".

She looked up the real data to show us what Jim must have seen. Again the graph is complex, has multiple scales and no indication of unit and was hence almost impossible for us to read (see Figure 8). Carol explained: "This graph shows the revs per minute of one extruder and all the sub-master batches [feeders] that feed it."

It is again important to be able to contrast this 'abnormal' graph with graphs of normal revolutions per minute; here they are available in the same figure by reference to the other two RPM lines. We again reconstruct in Figure 9 the main parts of the graph and suppress "irrelevant" features to assist readability. When we later interviewed Jim about these historical data screens, he explained that the straight parts in the white line with the arrows in Figure 8 "looked wrong". He said about a similar line in another RPM read-out that it "looked too good to be true". In other words, the variation in the white line should look more like the other variable lines - not a constant line. 


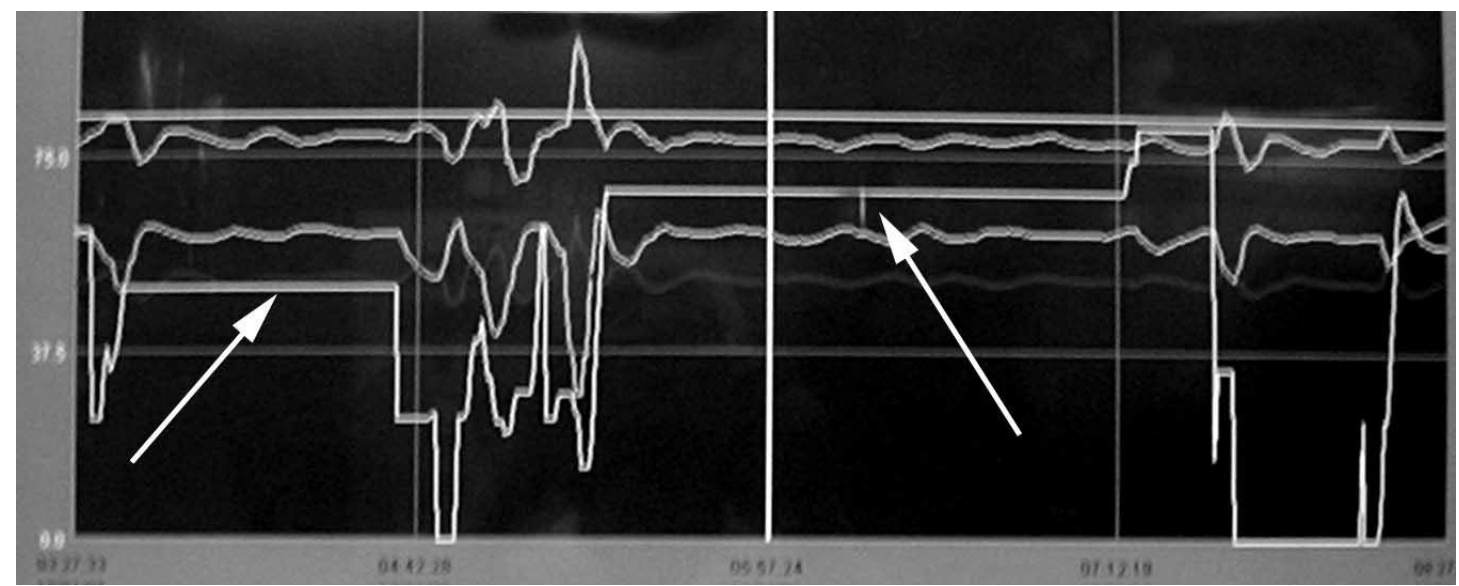

Figure 8 . The straight parts (indicated by white arrows) in the white line are too constant. The variation in this line should look more like the other lines (the top straight line is a set point and is therefore constant).

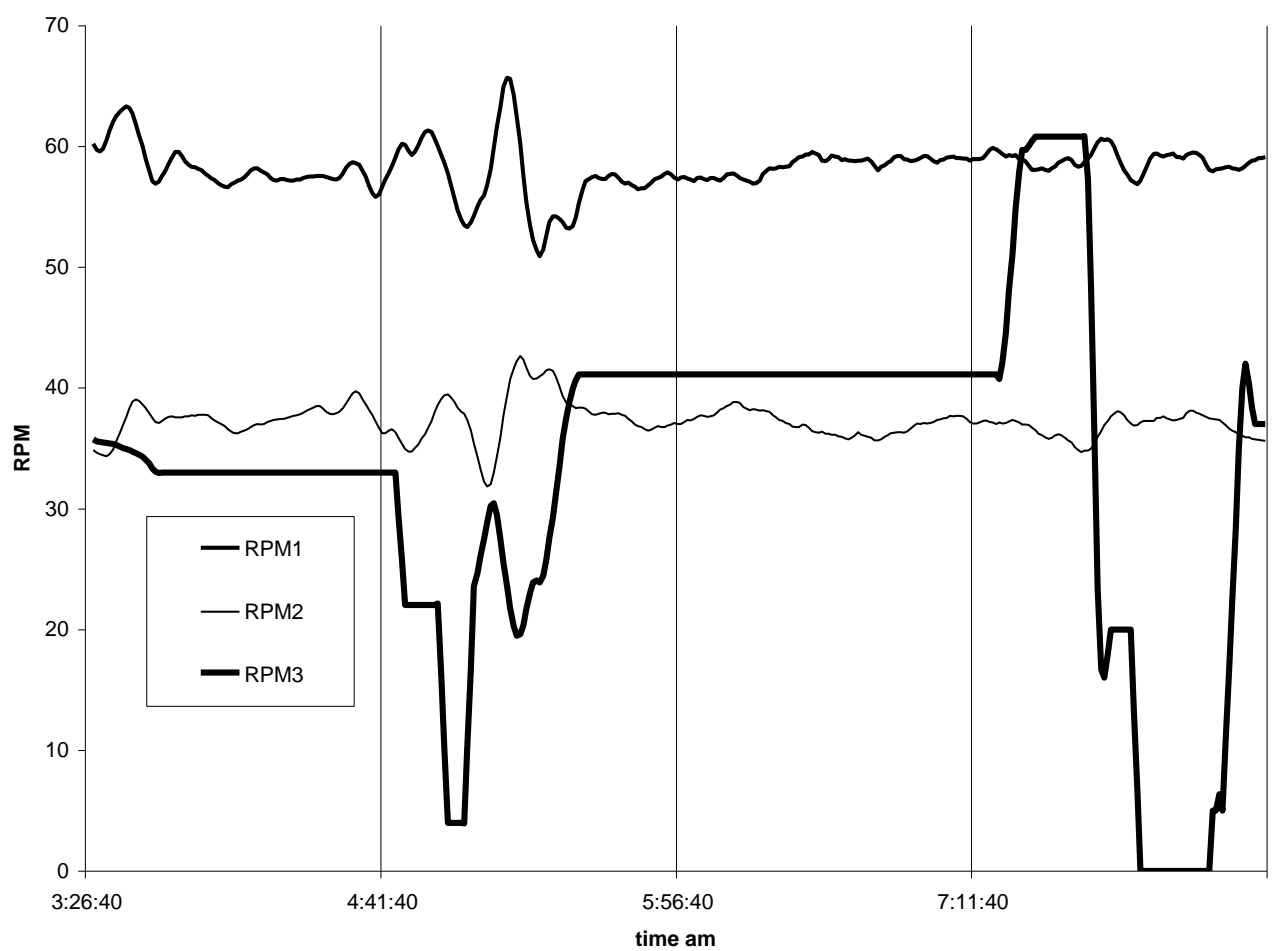

Figure 9. A reconstruction of the RPM graph (Figure 8) without horizontal scale lines, set point and main extruder RPM line. The third RPM line is looking wrong as it shows straight parts. A bubble burst occurred at about 4:40 am and repair took place at the end of this 5-hour period. 
Initially, we were again rather inclined to think that anyone could see that the straight parts in the RPM lines were odd. But when we discussed this with Carol, we found that interpreting the straight parts as odd was actually non-trivial. First, as we have seen in Figures 4 and 7, set points $d o$ yield straight lines in the graphs. RPM lines on the other hand always vary slightly. Hence whether or not to react to a straight line depends on mobilising some background knowledge that includes knowing that the graphs of set points are generally straight, knowledge that according to Carol, few shift leaders have. Second, it was drawn to our attention that the variation in the tension graphs (Figure 3) looks very different from the variation in the revolutions per minute (RPM) graph (Figure 8). Jim had to able to infer which graph was about which variable, tension or RPM from the "type of wiggly" or "smooth" variation. Jim also could infer, when we showed him Figure 8, that the spiky lines indicated bubble bursts - which was confirmed by Carol (the spiky lines can be seen from 04:40 am to 05:20 am). Thus it seemed that Jim could distinguish variables by the behaviour of their graphs and then could read some aspects of the process through the graph. However, we cannot conclude that the graphs in this second vignette were transparent to him or to Carol in the sense that neither could read the cause of the straight lines through the graph; they were mainly looking at the graph.

\section{CHARACTERISING JIM'S KNOWLEDGE}

The focus in this section is on how we might characterise the techno-mathematical literacies (TmL) that Jim had developed at work. Our starting point is to analyse the reciprocal relationship between graphical and experiential knowledge, and how each shaped meanings for the other. 
What did Jim know in order to locate the source of the problem in the first vignette? First he found the graphs among all those available that arose from data at the point of the shopfloor problem, so he was able to map the shop floor process on to the graphs, to situate the abstraction of the graphs into the process. What else did he know? $\mathrm{He}$ could distinguish the variables graphed by reference to their shape, their "wiggly factor" while suppressing all irrelevant features of the graphical display. By contrast, we had to rethink the graphs to highlight the important features and suppress the unimportant: Jim could do this spontaneously, and so could Carol. Jim also knew what "normality" in the process looked like (just as we remarked earlier that the nurses knew what normality would look like on a blood pressure chart of a baby).

We asked Carol about this and she asserted:

\footnotetext{
... the pattern was cycling - one of the inventory units was cycling and the other one had been very high and then had dropped for no reason and then gone back up again. You'd normally expect them [the graphs] to be flat [so] he has used his knowledge of the process to say "well these are the inventories, what you want is to have a constant tension", because otherwise you're putting stress into the tape and if you do that it's going to behave oddly at the bubble ...
}

It is tempting, therefore, to ascribe this to his experience and simply familiarity with the process. And in part, this is certainly true: Jim was a long-serving employee, with a deep knowledge of the production process. But it is also true that the graphs had become part of that experience: he had chosen to access them regularly, and took pride in looking for structure, especially unexpected structure, within them. We can safely assume that in searching for the unexpected, he also gained considerable familiarity with what was expected and routine. So his experience of the plant, his knowledge of what was normal and abnormal, was mediated by his knowledge of the graphs. 
It is, however, striking that Jim did not seem to use the graphs as conventional representations of the process (apart from seeing them as a historical trace of measuring tension). His natural mode of working was the reverse: only if he knew when and in which part of the process something had gone wrong, would he be searching for some corresponding abnormality in one of the many graphs to locate a possible source of the problem. As we pointed out earlier, he admitted that if he had only seen a "dip" on a graph as in Figure 6 but had no evidence from the process that anything was out of the ordinary, he would have ignored it - or as he put it, there would be "no cause for concern". This is a surprising but readily explainable point of view: to Jim the graphs did not represent the state of the process, nor did he know the physical and chemical processes represented by the graphs (the graphs just "looked wrong"). The graphs indexed possible sources of breakdowns that were already known.

By contrast, Carol was able to draw on certain kinds of disciplinary or codified knowledge that was not available to Jim. For example, Jim thought that the tension in the inventories affected the gauge of the film in the bubble. Asked what could cause the variability in the graph, he said:

It could be a seized roller, there are so many rollers up there on the inventory - might be a 100 [rollers] - and one seized roller would have an effect on the gauge, if the tape was not running freely and stopping for a period of time, it could stretch the tape which would affect the gauge. If you are running 15 micron, the tape might get a bit slack and the gauge might go down to 12 micron.

After our interview with Jim (which she attended), Carol emailed us to say that there was no such relation between tension and gauge - and her scientific explanation convinced us: 
There was a point I wanted to clarify; during your meeting with Jim he perceived that a stretching and relaxing of the tape would affect the gauge (I think he said from 15 microns to 13 microns, say) and so caused the bubble instability. I disagree with this. We certainly never saw a higher variability of gauge from this line, as you would expect if Jim were correct. Jim saw the instability, linked it in his head to the stretching/relaxing and assumed that the gauge was affected, since he was aware that gauge changes on a line can cause a change in bubble stability (when we deliberately change from one gauge to another, for example). I think the effect has to be more subtle than that, relating to crystalline stresses in the plastic, as I mentioned when we met.

What she mentioned when we met was the following:

That would cause bubble instability because you are putting different amounts of stress into the tape, and if you take the stress off again you cause strain-induced crystallisation, so there is a part of the tape which is harder or softer, or perhaps the whole tape is harder and then a few moments later it is softer. When that comes to the bubble it is working very hard to rack a tape that is hard and then suddenly the tape is soft.

Without question, gauge is the most salient and important variable of the process, and the achievement of its stability is a key object of activity. So it is not surprising the Jim assumed that instability was linked to gauge.

Another example of the difference between Carol and Jim's knowledge is in the language they used. We note here the difficulty we experienced in talking with Jim (but not Carol) about the graphs. During our interview we tried to invite Jim to talk about the features he saw in the graphs, but whenever we tried, he talked at length about the production process and the people who were involved whilst apparently ignoring the graphs in front of him. When we kept prompting and pointing at the graphs, he used terms such as "normal", "odd" and "dips" to describe graphical features, and he was, as we saw, willing to sketch what the dip looked like in the first 
vignette (Figure 5). Yet overall, Jim did not seem to have a language that we could understand to communicate his interpretations of the graphs. Summarising, we, along with Carol, employed a language of graphs in our communication (about cyclic or symmetric patterns, mean, variation) whereas Jim only used the language of the process.

\section{DISCUSSION}

The two vignettes concerning Jim's use of graphs were presented as a way to explore the limits of the validity of the transparency metaphor, to which we now return. Roth (2004) suggests that transparency is likely to occur if people are very familiar with the context and the graphs of this context:

In the workplace, experienced people no longer distinguish between graphs and the phenomena they stand for so that graphs become transparent in knowledgeable everyday actions, that is, they constitute tools-in-use that are not consciously attended to (p. 596).

Though we are convinced that this was true for the scientists (e.g. ecologists, water technicians, fish culturists) studied by Roth, our analyses show that within the activity system of the factory, graphs tend not to be transparent tools for making sense of the production system. In the first vignette odd-looking "dips" led the way to investigate the tension in one of the inventories, but nobody could see from the graph that the bearings were seized up. In the second vignette, the "straight" lines were unlike the revolution per minute lines of the other batches, but it was not possible to see from the graphs only that these straight parts were caused by false readings of a motor running backwards. The graphs were not transparent tools, but rather graph use could better characterised as mainly indexical because potential sources of problems were inferred from certain regularities or irregularities in the graphs. Our protagonists did not look 
through the graphs but at features of them as indicators of trouble, pinpointing when and where things went wrong.

Our research suggests that the points at which the graphs became incorporated into the activity system, they entered as abstractions of the work process, and for Jim, they became - over time - part of that process. When something goes wrong with the tools of the activity of producing film, Jim situated the graph into the system of tools, and thereby gave it a voice. These graphs are symbolic representations of the process with their own grammar and their own semantics. It is for this reason that their interpretation is not unproblematic, as there is an interaction between the meanings expressed by individuals, and those culturally embedded in the artefacts.

It is this symbolic dimension that has given rise to the notion of situated abstraction, the possibility of situating familiar knowledge of the activity within the abstracted representation of it (Noss \& Hoyles, 1996b). Thus we see that the notion of situated abstraction lends prominence to the role of symbolic tools in the processes of generating, expressing and sharing mathematical meanings within a particular community - that is, generating a language of communication of the relevant mathematical ideas for that community. Further when graphs are transparent tools-inuse, the sign (or representation) and referent become "fused" (Roth, 2003b).

Our vignettes raise questions about the graphs' representational function. The graphs could only play their indexical role due to the fact that they were representations of the measurements of a variable over particular time periods: because Jim knew that Figure 6 was a graph belonging to the inventory set points and tensions, he could indicate the problem's location. Yet the graphs were not representations of the problems causing dips or straight lines: Jim did not know what was causing the "odd" features in the graphs. This point illustrates, in our view, that graphs are not just tools; 
they are also representations and mediating signs. Hence a semiotic perspective, enhancing an activity-theoretical perspective, can provide a more detailed account of types of sign mediation and the limits of the transparency metaphor. As Bakhurst (1996) observed in reflecting on activity theory, the notion of semiotic mediation has been "marginalized in the Soviet tradition since the Stalin era" (p. 215). In much recent workplace research, tools, artefacts or instruments are broadly taken as mediating between subject and object of activity. But because mathematical "tools" are often signs such as tables and graphs, we also need a specific theory of semiotic mediation, which takes account of how different types of mathematical signs are used at work.

One way of gaining a more detailed account of sign use is provided by Peirce's semiotics. Peirce distinguishes icons, indices and symbols, where icons are subdivided into metaphors, images and diagrams (see e.g. Bakker \& Hoffmann, 2005; Stjernfelt, 2000). The main function of an index is to direct someone's attention to something (Peirce, 1976, Vol. 3, p. 887), and Jim's graph use can best be characterised as indexical - drawing attention to a particular location of the production process. In the vignettes, the graphs were also used as diagrams, that is complex signs of relations (or models), in this case within and between variables such as tension, set point and RPM. Peirce (1992, p. 394) also uses the notion of the depth of a sign to indicate the layers of interpretations made from a sign. This notion can help us take account of observations such as Jim being able to see transparently a bubble burst in Figure 8 , but not what was causing the straight line (a motor running backwards and yielding false readings). It can also highlight the richer scientific interpretations that Carol draws from the same signs, similarly without seeing through the graph. 
We want to end this discussion by conjecturing why there were differences between Roth's scientists and the protagonists in our vignettes. First, it seems Roth (2003a, b) focused the analysis of his case studies on "ideal" cases in which scientists did not consciously attend to the graphs as tools-in-use. Our vignettes, however, point to a need for a fuller account of the spectrum of transparency: Jim and Carol did see some production features through the graphs ("this is a bubble burst"), but not others. Such nuances do not easily come to the fore when the focus is on ideal cases of transparency or when signs are just seen as tools.

Second, a distinction that must be made between scientists' use of graphs and Jim's is the graphs' provenance - and this may partially account for the non-occurrence of the transparency phenomenon in our vignette. In the fish farm reported by Roth, the graphs were produced by the scientists themselves, who were fully conversant with the instrumentation techniques, and how the graphs were constructed. The graphs in the fish hatchery were actually part of the phenomena to be observed, at least from the point of view of the scientists. Carol had developed a similar relationship with the graphs; she looked at them everyday and had consciously set about gaining familiarity with their construction. She used techniques such as 'zooming in on smaller time periods' to increase her 'mastery' over with the shapes of the graphs so she was better able to spot abnormalities. Thus she could use the graphs to change what she could see and as manipulable tools in any investigation. By contrast, Jim and his colleagues had little idea about how the historical data was generated and how the graphs were constructed: the graphs were produced by some means, and by people, with whom they had no connection; and as we have seen they were complex and not designed for readability. Unlike the machines and material with which the operators interacted every day, these abstractions were grafted on to the activity, and had to be - more or 
less explicitly - situated into it. Unsurprisingly, only some employees succeeded in doing so. Jim had no access to these techniques.

Finally, if we want to characterise the graphs as tools-in-use, we have to take into account the division of labour and the corresponding division of knowledge. Jim needed Carol; Carol needed the maintenance team to find the exact sources of the production problems. But Carol heard from Jim what to investigate and the maintenance team heard from Carol what to look for. This point suggests that in addition to viewing the graphs as transparent tools-in-use, we can characterise them as boundary objects in the sense of Bowker and Star (1999): artefacts that might - under the right circumstances - serve to help to coordinate different perspectives of several communities of practice (see also Kent et al, in preparation).

The notion of boundary object provides an avenue for characterising graph use between different actors in the workplace activity systems, thus taking into account the division of knowledge and labour at the macro level. Because these boundary objects can also be signs, this perspective is compatible with a semiotic view at a more micro, individual level.

The extent to which Jim and Carol use the graphs as boundary objects for thinking about their respective activities is the extent to which each of them endows the graphs with the knowledge and familiarity of the objects in their own overlapping activity systems. The vignettes show how, at the boundary of expertise and responsibility between Carol and Jim, the graphs could serve as boundary objects which allowed them to communicate. In fact, this communication is in general lacking within the activity system of the factory as a whole, and even in Jim's case, only occurred as the graph's abnormality was evident to anyone (like Jim and a very few others) whose 
appreciation of normality includes the graphs. Carol expressed her wish that others than Jim could do the same:

There is definitely an opportunity that we are not exploiting - when shift leaders have been looking at the data and seen something anomalous, they want to know why - because they pride themselves on knowing the process. So if more shift leaders at least know how to access the data, they would be happier overall - at the end of their shift they could not only look at a pallet full of film rolls, but also look at the coloured charts showing how well they had controlled things, instead of one with lines all over the place.

\section{REFERENCES}

Bakhurst, D. (1996). Social memory in Soviet thought. In H. Daniels (Ed.), An introduction to Vygotsky (pp. 196-218). London: Routledge.

Bakker, A., \& Hoffmann, M. (2005). Diagrammatic reasoning as the basis for developing concepts: A semiotic analysis of students' learning about statistical distribution. Educational Studies in Mathematics, 60, 333-358.

Bowker, G. C., \& Star, S. L. (1999). Sorting things out. Classification and its consequences. Cambridge, MA: MIT Press.

Engeström, Y. (2001). Expansive learning at work: Toward an activity theoretical reconceptualization. Journal of Education and Work, 14(1), 133-156.

Kent, P., Noss, R., Bakker, A., Guile, D., \& Hoyles, C. (in preparation). Characterising the use of mathematical knowledge in boundary crossing situations at work. Submitted to Mind, Culture, and Activity. 
Meira, L. (1998). Making sense of instructional devices: The emergence of transparency in mathematical activity. Journal for Research in Mathematics Education, 29(2), 121-142.

Nathan, M., Carpenter, G. and Roberts, S. (2003). Getting by, not getting on: Technology in UK workplaces (Report by The Work Foundation iSociety Project). London: The Work Foundation.

Noss, R., \& Hoyles, C. (1996a). The visibility of meanings: Modelling the mathematics of banking. International Journal of Computers for Mathematical Learning, 1(1), 3-31.

Noss, R., \& Hoyles, C. (1996b). Windows on mathematical meanings: Learning cultures and computers. Dordrecht, the Netherlands: Kluwer Academic Publishers.

Noss, R., Pozzi, S., \& Hoyles, C. (1999). Touching epistomologies: Meanings of average and variation in nursing practice. Educational Studies in Mathematics, $40,25-51$.

Peirce, C. S. (1976). The new elements of mathematics (Eisele, C., Ed.) (Vol. I-IV). The Hague-Paris/Atlantic Highlands, N.J.: Mouton/Humanities Press.

Peirce, C. S. (1992). The essential Peirce. Selected philosophical writings. Vol. 1 (1867-1893). Bloomington: Indiana University Press.

Roth, W.-M. (2003a). Competent workplace mathematics: How signs become transparent in use. International Journal of Computers for Mathematical Learning, 8, 161-189. 
Roth, W.-M. (2003b). Toward an anthropology of graphing: Semiotic and activitytheoretic perspectives. Dordrecht, The Netherlands: Kluwer Academic Publishers.

Roth, W.-M. (2004). Emergence of graphing practices in scientific research. Journal of Cognition and Culture, 4(3\&4), 595-627.

Roth, W.-M., \& Bowen, G. M. (2003). When are graphs worth ten thousand words? An expert-expert study. Cognition and Instruction, 21(4), 429-473.

Stjernfelt, F. (2000). Diagrams as centerpiece of a Peircean epistemology. Transactions of the Charles S. Peirce Society, 36(2), 357-384.

Zuboff, S. (1988). In the age of the smart machine: The future of work and power. New York: Basic Books.

\footnotetext{
${ }^{\mathrm{i}}$ The Techno-mathematical Literacies in the workplace project [www.ioe.ac.uk/tlrp/technomaths] is funded by the Teaching and Learning Research Programme [www.tlrp.org], a programme of the U.K. Economic and Social Research Council, Award Number L139-25-0119.

ii Surprisingly, and contrary to our initial assumption, it turns out that experienced workers can distinguish some variations in film thickness by different feel and texture, for example the difference between 15 micron and 18 micron thickness, but not to the level of tenths of a micron that matter for controlling the process.
} 